University of Nebraska - Lincoln

DigitalCommons@University of Nebraska - Lincoln

Faculty Publications: Department of Entomology

$2-21-2019$

\title{
Resistance to greenbugs in the sorghum nested association mapping population
}

\author{
Sajjan Grover \\ University of Nebraska-Lincoln \\ Braden Wojahn \\ University of Nebraska-Lincoln \\ Suresh Varsani \\ University of Nebraska-Lincoln \\ Scott E. Sattler \\ University of Nebraska-Lincoln \& Wheat, Sorghum, and Forage Research Unit, USDA-ARS, \\ Scott.Sattler@ars.usda.gov \\ Joe Louis \\ University of Nebraska-Lincoln, joelouis@unl.edu
}

Follow this and additional works at: https://digitalcommons.unl.edu/entomologyfacpub

Part of the Entomology Commons

Grover, Sajjan; Wojahn, Braden; Varsani, Suresh; Sattler, Scott E.; and Louis, Joe, "Resistance to greenbugs in the sorghum nested association mapping population" (2019). Faculty Publications: Department of Entomology. 774.

https://digitalcommons.unl.edu/entomologyfacpub/774

This Article is brought to you for free and open access by the Entomology, Department of at DigitalCommons@University of Nebraska - Lincoln. It has been accepted for inclusion in Faculty Publications: Department of Entomology by an authorized administrator of DigitalCommons@University of Nebraska - Lincoln. 


\title{
Resistance to greenbugs in the sorghum nested association mapping population
}

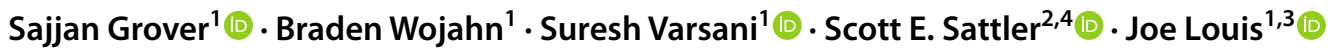

Received: 4 December 2018 / Accepted: 30 January 2019 / Published online: 21 February 2019

(c) Springer Nature B.V. 2019

\begin{abstract}
The greenbug, Schizaphis graminum, is a serious pest of sorghum (Sorghum bicolor). For the past several decades, resistant sorghum hybrids have been used to control greenbug populations. However, the durability of plant resistance is frequently challenged by evolution of new greenbug biotypes, and there is a continuous need for screening of resistant germplasm for its effective management in the field. Natural variation in sorghum plants/populations provides distinct approaches to identify novel sources of resistance against greenbugs. In this study, we used the recently developed sorghum nested association mapping (NAM) population parental lines to understand sources of sorghum resistance to greenbugs. Using choice and no-choice assays, we have identified SC265 and Segaolane as the resistant and susceptible lines, respectively, to greenbugs compared to the wild-type plants. The Electrical Penetration Graph (EPG) analysis revealed that the greenbugs spent significantly lesser time in the xylem and sieve element phases while feeding on the resistant NAM parental line, SC265, compared to the susceptible (Segaolane) and wild-type (RTx430) sorghum lines. In addition, the EPG results indicated that there is no significant difference in the time to first probe, time to reach first sieve element, pathway phase, and non-probing phase among the three sorghum plants, which suggests that the resistance factors present in the vascular tissues of the resistant line (SC265) potentially contribute to the resistance mechanisms against greenbugs. Overall, SC265 NAM parental line showed a combination of antixenotic and antibiotic-mediated resistance mechanisms against greenbugs, whereas the susceptible line Segaolane displayed the least resistance to greenbugs.
\end{abstract}

Keywords Antibiosis $\cdot$ EPG $\cdot$ Phloem $\cdot$ Schizaphis graminum $\cdot$ Sorghum

Handling Editor: Dagmar Voigt.

Electronic supplementary material The online version of this article (https://doi.org/10.1007/s11829-019-09679-y) contains supplementary material, which is available to authorized users.

Joe Louis

joelouis@unl.edu

1 Department of Entomology, University of Nebraska-Lincoln, Lincoln, NE 68583, USA

2 Department of Agronomy \& Horticulture, University of Nebraska-Lincoln, Lincoln, NE 68583, USA

3 Department of Biochemistry, University of Nebraska-Lincoln, Lincoln, NE 68583, USA

4 Wheat, Sorghum, and Forage Research Unit, USDA-ARS, Lincoln, NE 68583, USA

\section{Introduction}

Sorghum [Sorghum bicolor (L.) Moench (Poaceae)] is one of the world's most important monocot crops grown for food, feed, fooder, and/or fuel (Taylor et al. 2006). More recently, sorghum has garnered more attention as a food crop in Western countries due to its high nutrient content (de Morais Cardoso et al. 2017). In addition, sorghum is rich in bioactive phenolic compounds, which have beneficial effects on gut microbiota and on the pharmacology of diseases such as inflammation, dyslipidemia, cancer, and hypertension (de Morais Cardoso et al. 2017). Moreover, dryland agriculture is gaining momentum with crops such as sorghum due to the increased scarcity of water availability for irrigation ( $\mathrm{Li}$ et al. 2008). However, sorghum is also susceptible to numerous insect pests that can result in economic yield losses (Reddy 1988; Reddy et al. 2017; Sharma et al. 2017).

The greenbug, Schizaphis graminum Rondani (Hemiptera: Aphididae), is one of the key pests of sorghum and 
various other cultivated grasses (Morgham et al. 1994; Flinn et al. 2001; Royer et al. 2015). This species is found in the temperate parts of the world and across all states of the U.S. (Harvey et al. 1997; Burd and Porter 2006; Aljaryian and Kumar 2016). Greenbugs develop in the whorls of young seedling plants and predominantly colonize on the abaxial surface (lower side) of leaf. Similar to other aphids, greenbugs also ingest the sap from the phloem by inserting their stylets and sucking, while creating stylet sheaths and injecting toxic saliva into plants which cause leaf discoloration and kill plant tissues (Ma et al. 1990). Besides causing direct feeding damage, greenbugs also transmit viral diseases such as maize dwarf mosaic virus and sugarcane mosaic virus (Berger et al. 1987; Gray et al. 2002). The development of new greenbug biotypes adds additional complexity in controlling these aphids in field crops. More than 10 biotypes of greenbugs have been reported thus far, and among them there are highly damaging, such as the biotypes C, E, I, and K (Harvey and Hackerott 1969; Harvey et al. 1991, 1997).

Since the continued reliance on insecticides has led to the increased greenbug resistance to pesticides (Teetes et al. 1995; Peters et al. 1975; Sloderbeck et al. 1991; Zhu et al. 2000; Gao and Zhu 2002), host plant resistance is considered to be one of the most promising, safe, and sustainable pest management strategies, if used appropriately (Sharma and Ortiz 2002; Stout 2014; Koch et al. 2016). Among the different categories of resistance, antixenosis and antibiosis constitute the major mechanisms of plant resistance to aphids (Painter 1951; Kogan and Ortman 1978). Antibiosis has a detrimental physiological effect on the insect biology after feeding on the host plant (Painter 1951), whereas antixenosis negatively affects the insect behavior (mainly) by structural impact (Kogan and Ortman 1978). Plants synthesize a multitude of secondary metabolites that could have an antibiotic effect on aphids. Some of these metabolites can also act as insect-deterrent compounds, which can effectively deter the aphids from sustained sieve element feeding (Louis and Shah 2013; Nalam et al. 2018b).

Aphids use their slender stylets present in the piercing-sucking mouthparts to feed on phloem sap by piercing plant tissue and extracting plant fluids. The aphid stylet penetration activities are generally considered as cues to accept/ reject the plant (Powell et al. 2006). The Electrical penetration graph (EPG) technique has been successfully utilized to investigate the specifics of plant resistance to piercing-sucking insects (Tjallingii 1985). Monitoring this aphid probing behavior is critical to understand the localization of plant resistance and determine how plants engage their resistance components to restrict aphid feeding (Louis et al. 2012b; Nalam et al. 2018a). The direct current (DC)-EPG system records the electrical resistance fluctuations produced by the penetrating insect and the electromotive force (EMF) signal components that are generated as a result of the aphid feeding (Tjallingii 1985). This responsiveness to EMF components is utilized to differentiate between intracellular and intercellular aphid stylet tip positions. The obtained waveform pattern varies with the change of position of aphid stylets within plant tissues. For example, when the aphid stylet is inserted intercellularly, the voltage is positive and when inserted intracellularly, the voltage is negative (Tjallingii 2006), resulting in potential drops in the signal that correlate with the physiological condition and defense status of the host. Broadly, the EPG waveforms are categorized into four phases: pathway phase, xylem phase, sieve element phase, and non-probing phase. The pathway phase represents time spent by aphids in various activities such as insertion and withdrawal of stylets intercellularly and brief sampling of cells that happens intracellularly (Jiang and Walker 2001). The xylem and phloem phases represent ingestion of water and phloem sap, respectively (Tjallingii 2006). The nonprobing phase represents periods of no stylet movement.

Natural variation in crop plant populations is an excellent source for plant resistance to pests and pathogens (Gur and Zamir 2004; Meihls et al. 2013). Recently, a nested association mapping (NAM) panel consisting of 10 recombinant inbred line populations has been developed in sorghum for the dissection of complex traits (Bouchet et al. 2017). These ten NAM founder lines were selected to capture a substantial proportion of the global genetic diversity of sorghum inbred lines (Bouchet et al. 2017). In addition, a NAM population of 2214 recombinant inbred lines was generated by crossing a genetically diverse population of ten sorghum inbred lines to an elite reference line RTx430. Thus, the sorghum NAM population has a natural diversity of sorghum germplasm, and to date, the sorghum NAM lines have not been used to examine the novel sources of resistance to insect pests and it is possible that these lines could act as a rich genetic resource to elucidate the underlying genetic basis of sorghum resistance to greenbugs.

In this study, we utilized the founder sorghum NAM lines to elucidate the sources of sorghum resistance or susceptibility to greenbugs. The main objective of our study was to identify the most resistant and susceptible NAM founder lines against greenbugs using choice (antixenosis) and nochoice, developmental (antibiosis) assays, as well as the EPG technique to assess the feeding behavior of greenbugs on these lines.

\section{Materials and methods}

\section{Plant material}

Ten founder lines of sorghum NAM populations were obtained from USDA-GRIN global germplasm (USA), which were Ajabsido, Macia, P898012, SC35, SC265, 
SC283, SC971, SC1103, SC1345, and Segaolane. Sorghum genotypes, including the 'BCK60' genotype for insect rearing, were grown in Cone-Tainers (Ray Leach SC10; Stuewe \& Sons, Inc., Tangent, OR) filled with soil mixed with vermiculite and perlite (PRO-MIX BX BIOFUNGICIDE + MYCORRHIZAE, Premier Tech Horticulture Ltd., Canada) in the greenhouse with a 14-h-light/10h-dark photoperiod, $25^{\circ} \mathrm{C}$, and $50-60 \%$ relative humidity at the University of Nebraska-Lincoln (UNL), USA. Twoweek-old plants at the three-leaf stage (Vanderlip and Reeves 1972) were used for all the experiments.

\section{Insect colony}

Greenbugs (biotype I) colony was obtained from Dr. John D. Burd, USDA-ARS in Stillwater, Oklahoma, USA (Burd and Porter 2006). This colony was maintained on susceptible sorghum genotype 'BCK60' in a growth chamber with a 14-h-light/10-h-dark photoperiod, $140 \mu \mathrm{E} \mathrm{m}^{-2} \mathrm{~s}^{-1}$ light quality, $23{ }^{\circ} \mathrm{C}$, and $50-60 \%$ relative humidity. New plants were replaced with old, degenerated plants in growth chamber, whenever needed.

\section{Aphid bioassays}

Both no-choice and choice assays were performed with greenbugs against ten NAM parent lines. The experimental design for both assays was Completely Randomized Design (CRD), i.e., all plants were randomly arranged and infested with aphids. For no-choice assay, ten adult apterous aphids of similar age and condition were released on each plant and covered with tubular clear plastic cages ventilated with organdy fabric on the top of the cage. Total number of aphids, including both adults and nymphs were counted after 7 days of release on each plant. For choice assay, ten NAM parent lines, along with the control line RTx 430 were grown per pot (10 inches diameter by 9 inches height) at equal distance $(\sim 5.0 \mathrm{~cm})$. After 2 weeks of planting, when the sorghum genotypes reached the three-leaf stage (Vanderlip and Reeves 1972), 100 adult apterous aphids of similar age and condition were introduced at the center of pot on a filter paper placed on the soil substrate so that the aphids have equal access to all the genotypes and also allowed the aphids to freely move on all plants. Settled aphids on each plant were counted after $24 \mathrm{~h}$ of release. For no-choice and choice assays, we had 12 replications per treatment (no choice: 12 pots including one plant per pot, choice: 12 pots including 11 plants per pot) and the assays were replicated three times independently (no choice: $3 \times 12$ pots including one plant per pot, choice $3 \times 12$ pots including 11 plants per pot).

\section{Aphid feeding behavior analysis}

\section{EPG recording}

Sorghum genotypes identified from no-choice assay as the most resistant (SC265) and susceptible (Segaolane) lines, along with control, RTx430, were used for EPG monitoring to assess the feeding behavior of greenbugs. Two-week-old potted plants at the three-leaf stage were used for the EPG experiments. Adult apterous greenbugs were separately placed on these plants at the middle of the adaxial leaf lamina. The aphid wiring and experimental procedure were carried out as described previously (Nalam et al. 2018a). Briefly, a gold wire attached to copper electrode was glued to dorsum of aphids using silver conductive glue. The silver conductive glue was prepared by mixing $4 \mathrm{ml}$ water with a single drop of Triton X-100, $4 \mathrm{~g}$ water-soluble glue (Scotch clear paper glue, non-toxic; $3 \mathrm{M}$, St. Paul, MN, USA), and $4 \mathrm{~g}$ silver flake $(99.95 \%$, size, $8-10 \mu \mathrm{m}$, Inframat Advanced Materials, Manchester, CT, USA). Another copper electrode was inserted into the soil surrounding the potted plant. A Giga-8 EPG model (EPG Systems, Wageningen, The Netherlands) with a $10^{9} \Omega$ resistance amplifier was connected to both plant and insect electrodes and an adjustable plant voltage were used for assessing feeding behavior of greenbugs on sorghum genotypes. The EPG experiments were conducted at laboratory conditions at $22-24{ }^{\circ} \mathrm{C}$ and $40-45 \%$ RH under continuous light conditions. Adult apterous greenbugs were starved in an empty plastic petri dish for $1 \mathrm{~h}$ prior to the start of EPG recording. Recordings were made on eight plants (mix of three selected genotypes) at a time, which were placed randomly in a Faraday's cage. All EPG recordings were started between $11 \mathrm{AM}-12$ noon local time (U.S. Central Standard Time). We had 15 replications per plant genotype (NAM lines and control) of recordings for $8 \mathrm{~h}$. Previously, it was shown that 8 -h duration of recording is sufficient to quantify the different feeding activities on host plants and the different waveform patterns selected in this study are the aphid feeding behavior parameters that are correlated with host plant resistance (Pegadaraju et al. 2007; Louis et al. 2010, 2012a; Varsani et al. 2019). EPG acquisition software (Stylet ${ }^{+}$, EPG Systems, Wageningen, The Netherlands) was used to record waveforms of greenbugs feeding on sorghum plants.

\section{Feeding behavior parameters}

Several feeding behavior parameters, following a successive series of A to F, have been considered in this study. The duration of pathway phase (A, B, C, and F), xylem phase $(G)$, sieve element phase (E), and non-probing phases were recorded and calculated. The other parameters include time to first probe by aphid (time difference between starting 
of recording and first insertion of stylet into plant), time to first sieve element phase (time difference between starting of recording and initiation of sieve element phase), and number of potential drops during 8-h recording of waveforms were calculated. E1 and E2 show aphid salivation and passive ingestion of phloem sap, respectively, which were together considered as sieve element phase (E). Waveform characteristics, F, indicate derailment of aphid stylets showing penetration difficulties, which was not found during our waveform recordings. EPG analysis software $\left(\right.$ Stylet $^{+}$, EPG Systems, Wageningen, The Netherlands) was used to analyze the waveforms of greenbugs feeding on sorghum plants.

\section{Statistical analyses}

The no-choice and choice data were analyzed as a completely randomized design using a generalized linear mixed models (GLMM) for count data and the GLIMMIX procedure (Stroup et al. 2018), which fits statistical models to data with correlations or non-constant variability and where the response is not necessarily normally distributed (PROC GLIMMIX, SAS 9.3, SAS Institute). Negative binomial distribution was used to analyze the count data. The explanatory and response variables were sorghum genotypes and number of aphids counted on each plant after day 7 , respectively. Multiple comparisons were computed using Dunnett's adjustment, comparing the number of aphids per NAM parental lines vs the number of aphids on the control plant (Supp. Table 4). For EPG experiments, non-parametric Kruskal-Wallis test was used to compare the duration of six different feeding parameters/phases among three different sorghum lines (RTx430, SC265, Segaolane) using PROC NPAR1WAY procedure, considering the non-normally distributed data. Multiple comparisons between means of different treatments were carried out using SAS macro implementation of the Nemenyi and Dunn's tests (Elliott and Hynan 2011).

\section{Results}

\section{No-choice assay}

Greenbug survival and reproduction were low on the inbred line SC265, intermediate on RTx430, and high on Segaolane $(F=10.01 ; \mathrm{df}=10,121 ; P<0.0001 ;$ Fig. 1$), 7$ days post aphid infestation. We did not observe any significant differences in the number of aphids per plant on other sorghum NAM parental lines. Supp. Table 1 shows the mean number of greenbugs on different sorghum NAM parental lines and the wild-type RTx 430 .

\section{Choice assay}

We also performed antixenosis test with the same sorghum parental NAM lines by introducing adult apterous greenbugs at the center of the pot. The number of adult greenbugs that had settled on Segaolane plants were significantly higher, whereas SC265 plants had significantly fewer adult greenbugs after $24 \mathrm{~h}$ compared to the wild-type control

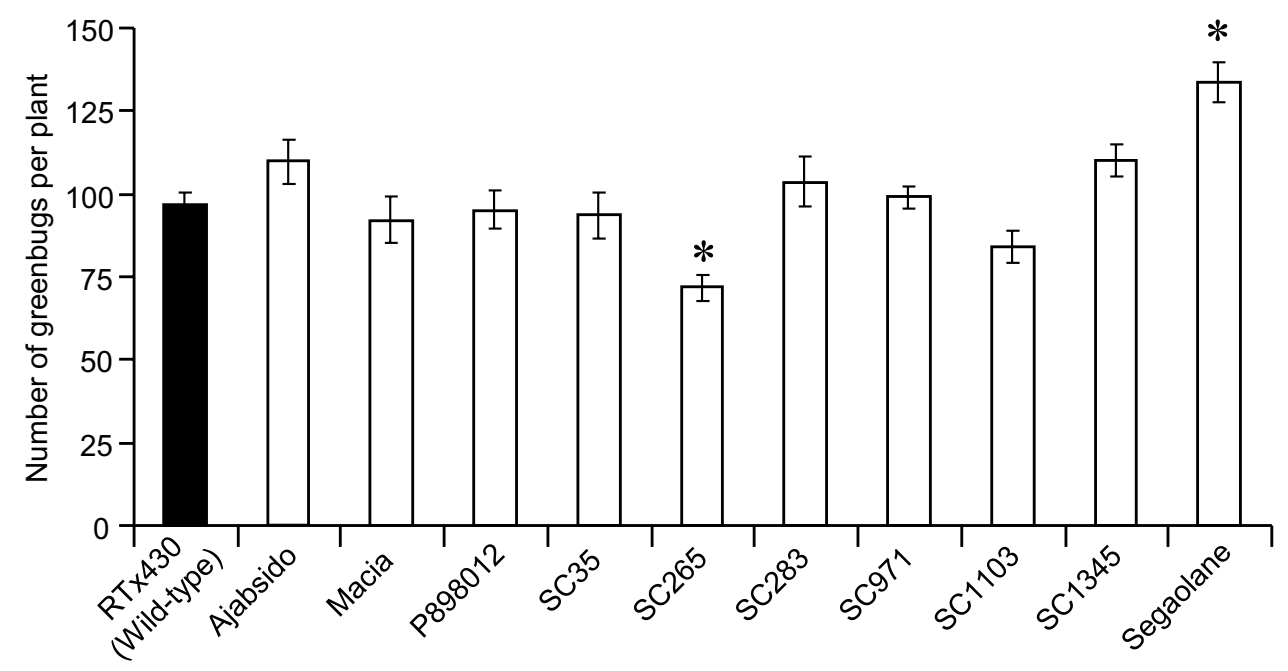

Sorghum NAM parental line

Fig. 1 Number of greenbugs, pooled for adults, and nymphs, per plant counted 7 days after infestation of 2-week-old sorghum plants with 10 adult apterous aphids per plant. $n=12$ pots per sorghum NAM parental line and wild-type including one plant per pot. All the infested plants were contained in cages. Asterisks indicate significant difference between sorghum NAM parental lines (unfilled bars) and wild-type RTx430 (filled bar) $(P<0.05)$. Bars show the mean pooled number of greenbug adults and nymphs per plant obtained for different sorghum NAM parental lines and the wild-type RTx430. Error bars represent \pm SEM 
plant $(\operatorname{RTx} 430)(F=10.35 ; \mathrm{df}=10,121 ; P<0.0001 ;$ Fig. 2$)$. Although not statistically different, SC35 plants also had fewer adult greenbugs after $24 \mathrm{~h}$ compared to the wild-type control plant (RTx430) $(P=0.06)$. Supp. Table 2 shows the mean number of adult greenbugs and percentage of adult greenbugs that had settled on different sorghum NAM parental lines and the wild-type RTx430.

\section{Feeding behavior parameters}

For the EPG studies, we used the two sorghum NAM parental lines SC265 and Segaolane, which have shown the greatest variation of resistance to greenbugs (Figs. 1, 2). RTx430 was used as the respective control. EPG waveform recordings were categorized into four different phases: pathway phase, xylem phase, sieve element phase, and non-probing phase. Representative EPG waveforms produced by greenbugs feeding on the sorghum NAM parental lines SC265 and Segaolane, and the RTx430 are shown in Fig. 3. Our results indicate that the greenbugs spent a significantly shorter time in the sieve element phase of the resistant SC265 line, compared to Segaolane and RTx430 lines $(\mathrm{df}=2 ; P=0.0219 ;$ Fig. 4$)$. Similarly, greenbugs spent significantly less time in the xylem phase of SC265 compared to RTx430 and Segaolane lines ( $\mathrm{df}=2 ; P=0.0022$; Fig. 4). There was no significant difference in the duration of nonprobing phase among all the three sorghum lines $(\mathrm{df}=2$; $P=0.81$; Fig. 4). Furthermore, although not significantly different, we observed a longer duration of pathway phase in the SC265 plants compared to RTx430 and Segaolane lines $(\mathrm{df}=2 ; P=0.2872$; Fig. 4). Our results also indicate that the greenbugs spent comparable amounts of time for the time to first probe and time to reach first sieve element phase among all the three sorghum lines $(\mathrm{df}=2 ; P=0.4285$ $\mathrm{df}=2 ; P=0.1957$, respectively; Fig. 5a). However, the total number of potential drops produced by greenbugs on SC265 were significantly higher than the other two sorghum plants, RTx430 and Segaolane ( $\mathrm{df}=2 ; P=0.0088$; Fig. 5b). Supp. Table 3 shows the mean time spent by greenbugs for various feeding activities on different sorghum NAM lines and the wild-type RTx 430 .

\section{Discussion}

Here, we provide evidence that the sorghum NAM founder line SC265 demonstrates both antibiosis- and antixenosis-mediated resistance to greenbugs, and it also deters greenbugs from sustained sieve element feeding. Our no-choice assay indicates varied levels of resistance to greenbugs in ten founder lines of the sorghum NAM population compared to RTx430, the common parent used for these NAM lines (Fig. 1). Furthermore, in the choice assay, there were significantly altered numbers of adult greenbugs settled on few sorghum lines compared to the control plant (RTx430) (Fig. 2). Several previous studies have shown that the reduced phloem sap ingestion from the host plants correlates with the enhanced resistance to

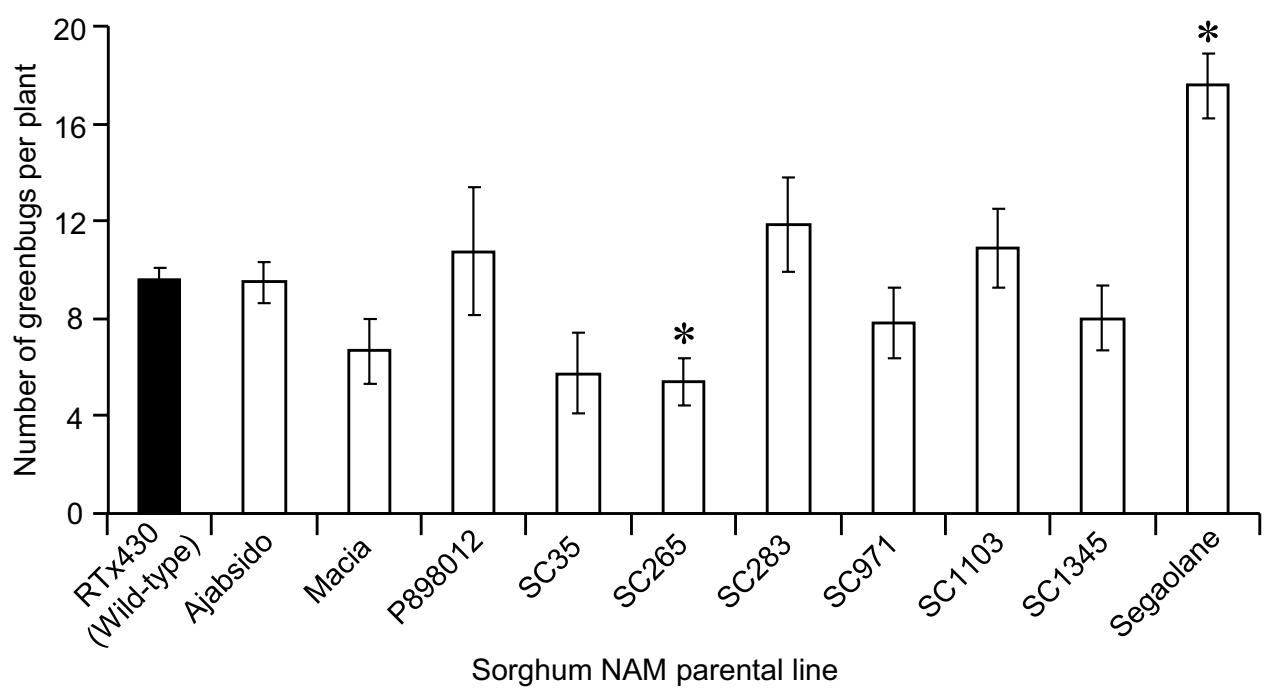

Fig. 2 Mean number of adult greenbugs found on each parental NAM sorghum line after $24 \mathrm{~h}$ of release of 100 adult greenbugs at the center of pot containing 11 different plants (10 sorghum NAM parental lines and wild-type/control) and free choice of aphids among these 11 plants. $n=12$ pots per sorghum NAM parental line/wild-type including 11 plants per pot. Asterisks above the bar indicate signifi- cant difference between sorghum NAM parental lines (unfilled bars) and wild-type RTx430 (filled bar) $(P<0.05)$. Bars show the mean number of greenbug adults per plant obtained for different sorghum NAM parental lines and the wild-type RTx430. Error bars represent \pm SEM 

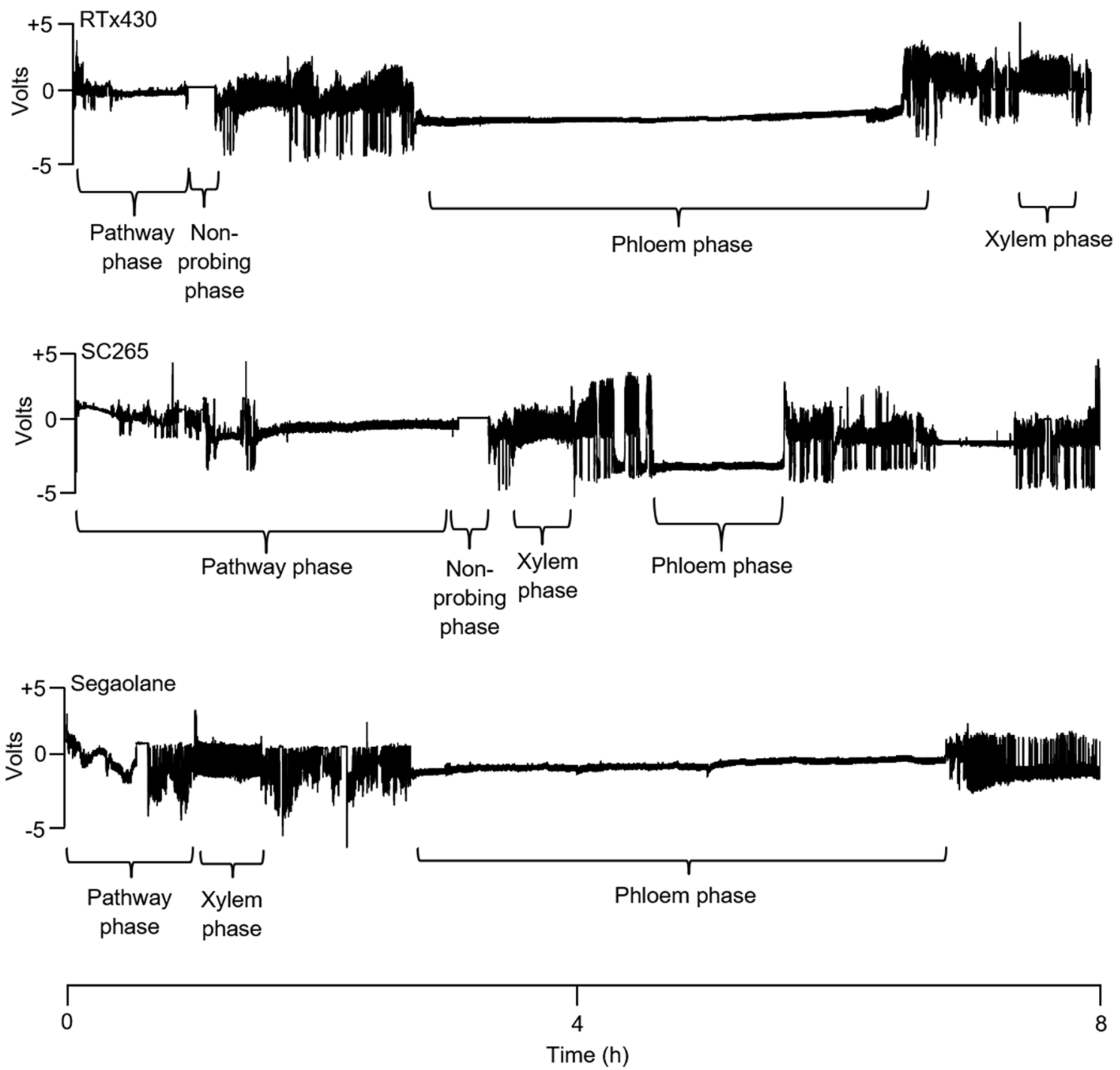

Fig. 3 Representative EPG waveform patterns of greenbug feeding on the sorghum RTx430, SC265, and Segaolane plants. The different patterns represent different phases of aphid probing on the sorghum plants over an 8-h period of EPG recording

aphids. For example, soybean aphids (Aphis glycines Matsumura; Hemiptera: Aphididae) fed significantly less from the sieve elements of soybean cultivars that exhibit antibiosis (Diaz-Montano et al. 2007; Zhu et al. 2011). Similar results have been shown in other plant-hemipteran systems, such as green peach aphid (Myzus persicae Sulzer; Hemiptera: Aphididae) feeding on Arabidopsis thaliana L. (Heynh.) (Brassicaceae) and Capsicum baccatum L. (Solanaceae), greenbugs on switchgrass [Panicum virgatum L. (Poaceae)], and Asian citrus psyllid Diaphorina citri Kuwayama (Hemiptera: Liviidae) on citrus (Pegadaraju et al. 2007; Koch et al. 2015; George et al. 2017; George and Lapointe 2018; Sun et al. 2018). Besides the chemical substances present in the phloem sap of resistant plants, it is possible that the presence of morphological/physical barriers on host plants can also contribute to difficulties in stylet penetration and sustainment for sapsucking insect feeding (Baldin et al. 2017; George et al. 2017). Such strong antixenosis, in some cases, can lead to starvation and death of the insects, when suitable host plants are unavailable (Smith 2005). Because our results showed that the time to first probe and the time to reach first sieve element phase were comparable for the SC265 NAM line and the other lines tested, it is highly likely that the resistance factors present in the vascular tissues contribute to the antixenotic-mediated resistance to greenbugs. Occasionally, it is difficult to differentiate between antibiosis and antixenosis (Smith 2005), and possibly the strong antibiotic factors present in the vascular tissues of SC265 NAM line may contribute to antixenotic-mediated resistance, which deter the aphids from settling on the host and feeding continuously from the phloem sap. 
Fig. 4 Total time spent by greenbugs for different feeding behavior parameters on each sorghum NAM parental line and the wild-type RTx430 during an 8-h period of EPG recording. $n=15$. Asterisks above the bar indicate significant difference based on Kruskal-Wallis test and multiple comparisons $(P<0.05)$. Bars show the mean values obtained for different sorghum NAM parental lines and the wild-type RTx430. Error bars represent \pm SEM

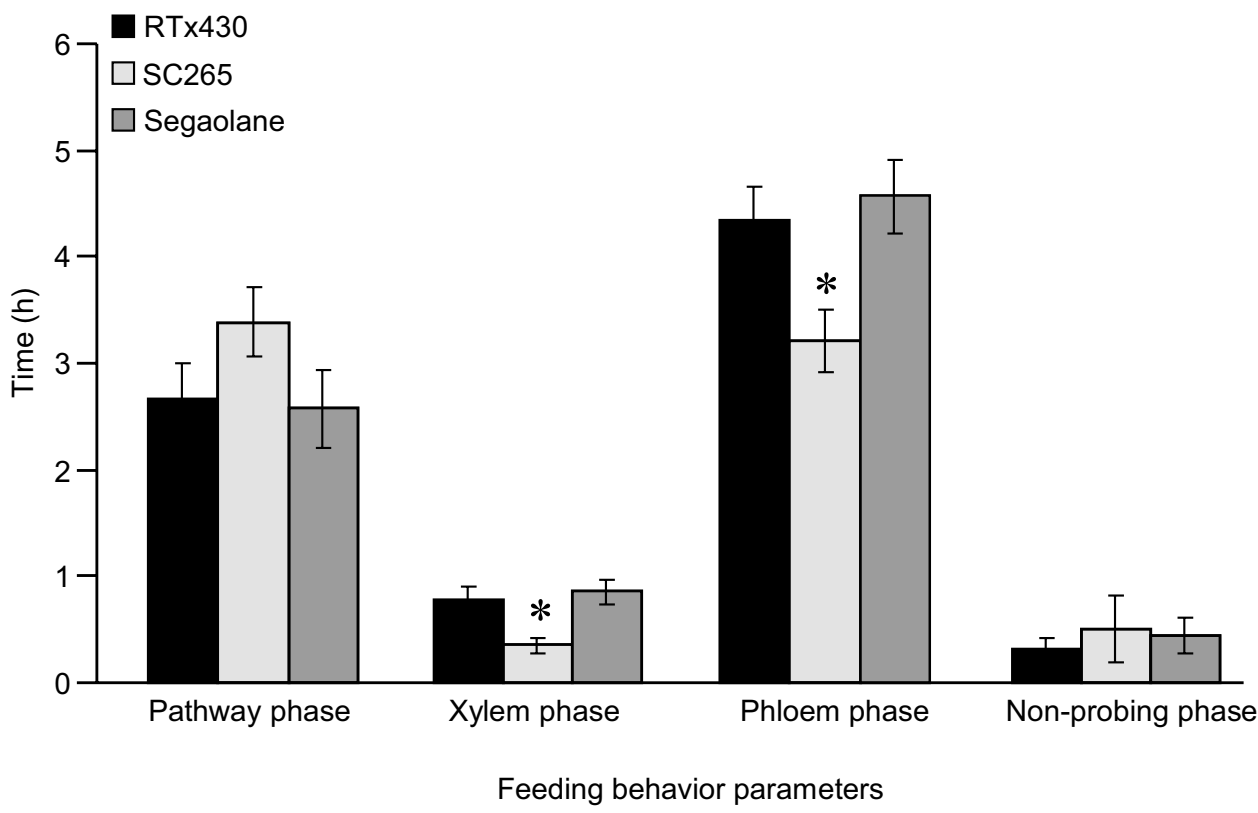

The sorghum NAM parental line, Segaolane, which was highly susceptible to greenbugs in both the choice and nochoice assays compared to the wild-type and resistant sorghum lines, was also found to be susceptible against the sugarcane aphid, Melanaphis sacchari Zehntner (Hemiptera: Aphididae) (Teetes et al. 1995), a serious pest of sorghum in the U.S. since 2013 (Armstrong et al. 2015). This result suggests that the Segaolane might produce susceptibility factors that function in facilitating aphid colonization across aphid species. For example, it was shown that compounds derived from LIPOXYGENASE 5 (LOX5) that encodes a 9-lipoxygenase promoted enhanced aphid fecundity on Arabidopsis (Nalam et al. 2012, 2018b). In addition, green peach aphid feeding on potato plants (Solanum tuberosum L.; Solanaceae) have demonstrated an enhanced accumulation of 9-LOX products (Gosset et al. 2009), which may also contribute to aphid susceptibility in potato. Although the exact compounds/metabolites that contribute to susceptibility in Segaolane are not known, it is highly plausible that phloem sap-sucking insects encounter these factors that aid their colonization of sorghum plants.

Our EPG study indicates that the resistance factors present in the SC265 lines may be phloem-localized. However, we observed a significantly higher number of potential drops in the resistant sorghum SC265 line, which corresponds to an increase intracellular punctures by aphid stylets. Increased potential drops have been found to be correlated with plant resistance in several other plant-aphid interactions. For example, pea aphids (Acyrthosiphon pisum Harris; Hemiptera: Aphididae) when fed on a resistant legume variety had significantly higher number of potential drops compared to the pea aphids that were fed on a susceptible legume variety (Gao et al. 2008). Similarly, soybean aphids feeding on soybean genotypes that exhibit antibiosis and antixenosis had significantly higher number of potential drops compared to the soybean aphid-tolerant and susceptible genotypes (Baldin et al. 2018). Taken together, these studies suggest that the brief sampling of cells by aphid stylets eventually lead to host plant acceptance or rejection, and the higher number of potential drops has been correlated with enhanced resistance to aphids (Tjallingii 2006; Chandran et al. 2013; Baldwin et al. 2018).

In addition to antibiosis and antixenosis, tolerance has been identified as a category of resistance to control insect pests (Painter 1951; Smith 2005). Unlike antibiosis and antixenosis, tolerance is a plant characteristic, which does not interfere with insect pest's biology or behavior (Painter 1951; Smith 2005; Koch et al. 2016). Tolerance aids the plant to recover or withstand from the insect damage through growth and compensatory physiological processes (Koch et al. 2016). Although not characterized in this study, it would be intriguing to screen sorghum NAM parental lines that exhibit tolerance traits to greenbugs. In summary, this study provided the foundation to further explore the role of key genes, signaling networks, defense pathways, and/ or regulatory mechanisms that underlie sorghum resistance to greenbugs. In addition, the information presented in this study potentially contribute to the sorghum breeding programs that are aimed at developing novel pest management strategies and increasing the level and durability of resistance in sorghum against phloem sap-sucking insects. 

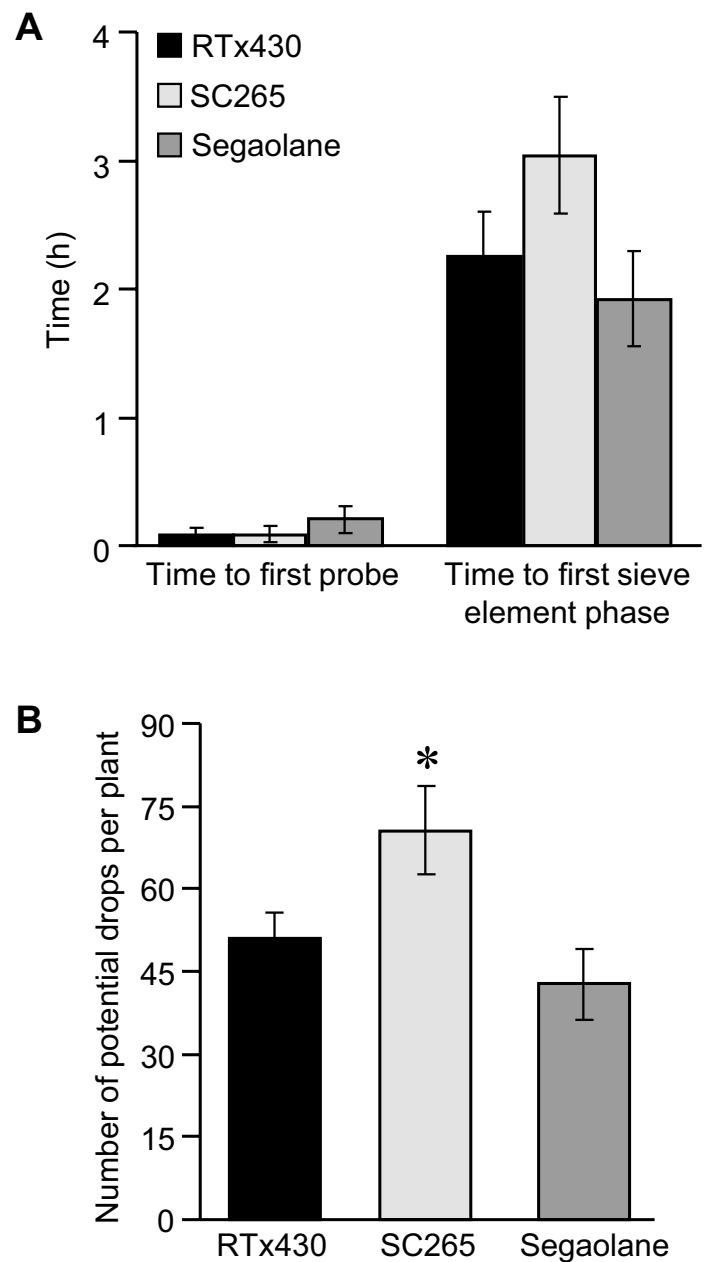

Fig. 5 a Total time spent by greenbugs to first probe and first sieve element phase on different sorghum NAM parental lines and the wild-type RTx430 during an 8-h period of EPG recording. No significant differences were observed among different sorghum NAM parental lines and the wild-type RTx430. b Mean number of potential drops by greenbugs on different sorghum NAM parental lines during an 8-h period of EPG recording. For $(\mathbf{a}, \mathbf{b}), n=15$. Asterisks above the bar indicate significant difference based on Kruskal-Wallis test and multiple comparisons using Nemenyi and Dunn's tests $(P<0.05)$. Bars show the mean values obtained for different sorghum NAM parental lines and the wild-type RTx430. Error bars represent \pm SEM

Acknowledgements We thank Dr. Kyle Koch (University of NebraskaLincoln, USA) for providing the greenbug colony. Braden Wojahn was supported by Undergraduate Creative Activities and Research Experience (UCARE) funds from the University of Nebraska-Lincoln, USA. This work was partially supported by the Nebraska Agricultural Experiment Station with funding from the Hatch Act (Accession \# 1007272) through the USDA National Institute of Food and Agriculture to Joe Louis and funds from USDA-ARS (58-3042-6-070).

\section{References}

Aljaryian R, Kumar L (2016) Changing global risk of invading greenbug Schizaphis graminum under climate change. Crop Prot 88:137-148
Armstrong JS, Rooney WL, Peterson GC, Villenueva RT, Brewer MJ, Sekula-Ortiz D (2015) Sugarcane aphid (Hemiptera: Aphididae): host range and sorghum resistance including cross-resistance from greenbug sources. J Econ Entomol 108:576-582

Baldin EL, L. PL, Cruz R, Morando IF, Silva JPF, Bentivenha LRS, Tozin, Rodrigues TM (2017) Characterization of antixenosis in soybean genotypes to Bemisia tabaci (Hemiptera: Aleyrodidae) biotype B. J Econ Entomol 110:1869-1876

Baldin EL, L. MD, Stamm JPF, Bentivenha KG, Koch TM, HengMoss, Hunt TE (2018) Feeding behavior of Aphis glycines (Hemiptera: Aphididae) on soybeans exhibiting antibiosis, antixenosis, and tolerance resistance. Fla Entomol 101:223-228

Berger PH, Zeyen RJ, Groth JV (1987) Aphid retention of maize dwarf mosaic virus (potyvirus): epidemiological implications. Ann Appl Biol 111:337-344

Bouchet S, Olatoye MO, Marla SR, Perumal R, Tesso T, Yu J, Tuinstra M, Morris GP (2017) Increased power to dissect adaptive traits in global sorghum diversity using a nested association mapping population. Genetics 206:573-585

Burd JD, Porter DR (2006) Biotypic diversity in greenbug (Hemiptera: Aphididae): characterizing new virulence and host associations. J Econ Entomol 99:959-965

Chandran P, Reese JC, Khan SA, Wang D, Schapaugh W, Campbell LR (2013) Feeding behavior comparison of soybean aphid (Hemiptera: Aphididae) biotypes on different soybean genotypes. J Econ Entomol 106:2234-2240

de Morais Cardoso L, Pinheiro SS, Martino HSD, Pinheiro-Sant'Ana HM (2017) Sorghum (Sorghum bicolor L.): nutrients, bioactive compounds, and potential impact on human health. Crit Rev Food Sci Nutr 57:372-390

Diaz-Montano J, Reese JC, Louis J, Campbell LR, Schapaugh WT (2007) Feeding behavior by the soybean aphid (Hemiptera: Aphididae) on resistant and susceptible soybean genotypes. J Econ Entomol 100:984-989

Elliott AC, Hynan LS (2011) A SAS $®$ macro implementation of a multiple comparison post hoc test for a Kruskal-Wallis analysis. Comput Methods Programs Biomed 102:75-80

Flinn M, Smith CM, Reese JC, Gill B (2001) Categories of resistance to greenbug (Homoptera: Aphididae) biotype I in Aegilops tauschii germplasm. J Econ Entomol 94:558-563

Gao J-R, Zhu KY (2002) Increased expression of an acetylcholinesterase gene may confer organophosphate resistance in the greenbug, Schizaphis graminum (Homoptera: Aphididae). Pestic Biochem Physiol 73:164-173

Gao L-L, Klingler JP, Anderson JP, Edwards OR, Singh KB (2008) Characterization of pea aphid resistance in Medicago truncatula. Plant Physiol 146:996-1009

George J, Lapointe SL (2018) Host plant resistance associated with Poncirus trifoliata influences the oviposition, larval development and adult emergence of Asian citrus psyllids, Diaphorina citri (Hemiptera: Liviidae). Pest Manag. Sci. https://doi.org/10.1002/ ps.5113

George J, Ammar E-D, Hall DG, Lapointe SL (2017) Sclerenchymatous ring as a barrier to phloem feeding by Asian citrus psyllid: evidence from electrical penetration graph and visualization of stylet pathways. PLoS ONE 12:e0173520

Gosset V, Harmel N, Göbel C, Francis F, Haubruge E, Wathelet J-P, Jardin P, Feussner I, Fauconnier M-L (2009) Attacks by a piercing-sucking insect (Myzus persicae Sulzer) or a chewing insect (Leptinotarsa decemlineata Say) on potato plants (Solanum tuberosum L.) induce differential changes in volatile compound release and oxylipin synthesis. J Exp Bot 60:1231-1240

Gray SM, Smith DM, Barbierri L, Burd J (2002) Virus transmission phenotype is correlated with host adaptation among genetically diverse populations of the aphid Schizaphis graminum. Phytopathology 92:970-975 
Gur A, Zamir D (2004) Unused natural variation can lift yield barriers in plant breeding. PLoS Biol 2:e245

Harvey TL, Hackerott HL (1969) Recognition of a greenbug biotype injurious to sorghum. J Econ Entomol 62:776-779

Harvey TL, Kofoid KD, Martin TJ, Sloderbeck PE (1991) A new greenbug virulent to E-biotype resistant sorghum. Crop Sci 31:1689-1691

Harvey TL, Wilde GE, Kofoid KD (1997) Designation of a new greenbug, biotype K, injurious to resistant sorghum. Crop Sci 37:989-991

Jiang YX, Walker GP (2001) Pathway phase waveform characteristics correlated with length and rate of stylet advancement and partial stylet withdrawal in AC electrical penetration graphs of adult whiteflies. Entomol Exp Appl 101:233-246

Koch KG, Palmer N, Stamm M, Bradshaw JD, Blankenship E, Baird LM, Sarath G, Heng-Moss TM (2015) Characterization of greenbug feeding behavior and aphid (Hemiptera: Aphididae) host preference in relation to resistant and susceptible tetraploid switchgrass populations. BioEnergy Res 8:165-174

Koch KG, Chapman K, Louis J, Heng-Moss T, Sarath G (2016) Plant tolerance: a unique approach to control hemipteran pests. Front. Plant Sci. 7

Kogan M, Ortman EF (1978) Antixenosis-a new term proposed to define Painter's "nonpreference" modality of resistance. Bull Entomol Soc Am 24:175-176

Li H, Payne WA, Michels GJ, Rush CM (2008) Reducing plant abiotic and biotic stress: drought and attacks of greenbugs, corn leaf aphids and virus disease in dryland sorghum. Environ Exp Bot 63:305-316

Louis J, Shah J (2013) Arabidopsis thaliana-Myzus persicae interaction: shaping the understanding of plant defense against phloem-feeding aphids. Front Plant Sci 4:213

Louis J, Leung Q, Pegadaraju V, Reese JC, Shah J (2010) PAD4-dependent antibiosis contributes to the ssi2-conferred hyper-resistance to the green peach aphid. Mol Plant-Microbe Interact 23:618-627

Louis J, Gobbato E, Mondal HA, Feys BJ, Parker JE, Shah J (2012a) Discrimination of Arabidopsis PAD4 activities in defense against green peach aphid and pathogens. Plant Physiol 158:1860-1872

Louis J, Singh V, Shah J (2012b) Arabidopsis thaliana - aphid interaction. Arabidopsis Book 10:e159

Ma R, Reese JC, Black WC, Bramel-Cox P (1990) Detection of pectinesterase and polygalacturonase from salivary secretions of living greenbugs, Schizaphis graminum (Homoptera: Aphididae). J Insect Physiol 36:507-512

Meihls LN, Handrick V, Glauser G, Barbier H, Kaur H, Haribal MM, Lipka AE, Gershenzon J, Buckler ES, Erb M, Köllner TG, Jander G (2013) Natural variation in maize aphid resistance is associated with 2,4-dihydroxy-7-methoxy-1,4-benzoxazin-3-one glucoside methyltransferase activity. Plant Cell 25:2341-2355

Morgham AT, Richardson PE, Campbell RK, Burd JD, Eikenbary RD, Sumner LC (1994) Ultrastructural responses of resistant and susceptible wheat to infestation by greenbug biotype $\mathrm{E}$ (Homoptera: Aphididae). Ann Entomol Soc Am 87:908-917

Nalam VJ, Keeretaweep J, Sarowar S, Shah J (2012) Root-derived oxylipins promote green peach aphid performance on Arabidopsis foliage. Plant Cell 24:1643-1653

Nalam V, Louis J, Patel M, Shah J (2018a) Arabidopsis-Green Peach Aphid interaction: rearing the insect, no-choice and fecundity assays, and electrical penetration graph technique to study insect feeding behavior. Bio-protocol 8(15):e2950

Nalam V, Louis J, Shah J (2018b) Plant defense against aphids, the pest extraordinaire. Plant Sci. https://doi.org/10.1016/j.plant sci.2018.04.027

Painter RH (1951) Insect resistance in crop plants. The Macmillan Company, New York

Pegadaraju V, Louis J, Singh V, Reese JC, Bautor J, Feys BJ, Cook G, Parker JE, Shah J (2007) Phloem-based resistance to green peach aphid is controlled by Arabidopsis PHYTOALEXIN DEFICIENT4 without its signaling partner ENHANCED DISEASE SUSCEPTIBILITY1. Plant J 52:332-341

Peters DC, Wood EA, Starks KJ (1975) Insecticide resistance in selections of the greenbug. J Econ Entomol 68:339-340

Powell G, Tosh CR, Hardie J (2006) Host plant selection by aphids: behavioral, evolutionary, and applied perspectives. Annu Rev Entomol 51:309-330

Reddy KVS (1988) Assessment of on-farm yield losses in sorghum due to insect pests. Int J Trop Insect Sci 9:679-685

Reddy PS, Bhagwat VR, Prasad GS, Tonapi VA (2017) Breeding for insect resistance in sorghum and millets. In: Breeding insect resistant crops sustainable agriculture. Springer, Singapore, pp 231-264

Royer TA, Pendleton BB, Elliott NC, Giles KL (2015) Greenbug (Hemiptera: Aphididae) biology, ecology, and management in wheat and sorghum. J Integr Pest Manage 6:19

Sharma HC, Ortiz R (2002) Host plant resistance to insects: an ecofriendly approach for pest management and environment conservation. J Environ Biol 23:111-135

Sharma S, Kooner R, Arora R (2017) Insect pests and crop losses. In: Breeding insect resistant crops sustainable agriculture. Springer, Singapore, pp 45-66

Sloderbeck PE, Chowdhury MA, DePew LJ, Buschman LL (1991) Greenbug (Homoptera: Aphididae) resistance to parathion and chlorpyrifos-methyl. J Kans Entomol Soc 64:1-4

Smith CM (2005) Plant resistance to arthropods: molecular and conventional approaches, Springer

Stout MJ (2014) Host-plant resistance in pest management-chap. 1. In: Abrol DP (ed) Integrated pest management. Academic Press, San Diego, pp 1-21

Stroup WW, Milliken GA, Claassen EA, Wolfinger RD. (2018) SAS® for mixed models: introduction and basic applications. Cary: SAS Institute Inc.

Sun M, Voorrips RE, Steenhuis-Broers G, Van't W, Westende, Vosman B (2018) Reduced phloem uptake of Myzus persicae on an aphid resistant pepper accession. BMC Plant Biol 18:138

Taylor JRN, Schober TJ, Bean SR (2006) Novel food and non-food uses for sorghum and millets. J Cereal Sci 44:252-271

Teetes GL, Manthe CS, Peterson GC, Leuschner K, Pendleton BB (1995) Sorghum resistant to the sugarcane aphid, Melanaphis sacchari (Homoptera: Aphididae), in Botswana and Zimbabwe. Int J Trop Insect Sci 16:63-71

Tjallingii WF (1985) Electrical nature of recorded signals during stylet penetration by aphids. Entomol Exp Appl 38:177-186

Tjallingii WF (2006) Salivary secretions by aphids interacting with proteins of phloem wound responses. J Exp Bot 57:739-745

Vanderlip RL, Reeves HE (1972) Growth stages of sorghum [Sorghum bicolor (L.) Moench]. Agron J 64:13-16

Varsani S, Grover S, Zhou S, Koch KG, Huang P-C, Kolomiets MV, Williams WP, Heng-Moss T, Sarath G, Luthe DS, Jander G, Louis J (2019) 12-Oxo-phytodienoic acid acts as a regulator of maize defense against corn leaf aphid. Plant Physiol. https://doi. org/10.1104/pp.18.01472

Zhu KY, Gao J-R, Starkey SR (2000) Organophosphate resistance mediated by alterations of acetylcholinesterase in a resistant clone of the greenbug, Schizaphis graminum (Homoptera: Aphididae). Pestic Biochem Physiol 68:138-147

Zhu L, Reese JC, Louis J, Campbell L, Chen M-S (2011) Electrical penetration graph analysis of the feeding behavior of soybean aphids on soybean cultivars with antibiosis. J Econ Entomol 104:2068-2072

Publisher's Note Springer Nature remains neutral with regard to jurisdictional claims in published maps and institutional affiliations. 


\section{Supplementary Table 1}

\begin{tabular}{|c|c|}
\hline Genotype & Mean \pm SE \\
\hline RTx430 (Wild-type) & $96.58 \pm 3.84$ \\
\hline Ajabsido & $114.25 \pm 7.01$ \\
\hline Macia & $92.00 \pm 6.98$ \\
\hline P898012 & $95.08 \pm 5.63$ \\
\hline SC1103 & $84.25 \pm 4.89$ \\
\hline SC1345 & $110.17 \pm 4.78$ \\
\hline SC265 & $71.92 \pm 3.95 *$ \\
\hline SC283 & $103.67 \pm 7.60$ \\
\hline SC35 & $93.50 \pm 7.18$ \\
\hline SC971 & $98.92 \pm 3.41$ \\
\hline Segaolane & $133.75 \pm 6.09 *$ \\
\hline
\end{tabular}

No-choice assay: Data from Figure 1 presented as a table. Asterisks indicate significant difference relative to wild-type, $\mathrm{RTx} 430(P<0.05)$. 


\section{Supplementary Table 2}

\begin{tabular}{|c|c|}
\hline Genotype & Mean \pm SE \\
\hline RTx430 (Wild-type) & $9.58 \pm 0.53$ \\
\hline Ajabsido & $9.50 \pm 0.84$ \\
\hline Macia & $6.67 \pm 1.35$ \\
\hline P898012 & $10.75 \pm 2.62$ \\
\hline SC1103 & $10.91 \pm 1.60$ \\
\hline SC1345 & $8.00 \pm 1.33$ \\
\hline SC265 & $5.41 \pm 0.94 *$ \\
\hline SC283 & $11.83 \pm 1.94$ \\
\hline SC35 & $5.75 \pm 1.67$ \\
\hline SC971 & $7.83 \pm 1.48$ \\
\hline Segaolane & $17.58 \pm 1.34 *$ \\
\hline
\end{tabular}

Choice assay: Data from Figure 2 presented as a table. Asterisks indicate significant difference relative to wild-type, $\mathrm{RTx} 430(P<0.05)$.

\begin{tabular}{|c|c|c|c|c|c|c|c|c|c|c|c|}
\hline \multicolumn{10}{|c|}{ Genotypes } \\
\hline Ajabsido & Macia & P898012 & RTx430 & SC1103 & SC1345 & SC265 & SC283 & SC35 & SC971 & Segaolane & Total \\
\hline 1.12 & 1.61 & 0.80 & 0.80 & 0.48 & 0.16 & 0.16 & 0.80 & 0.16 & 0.16 & 0.96 & 7.21 \\
\hline 0.80 & 0.48 & 0.32 & 0.72 & 0.64 & 0.96 & 0.32 & 0.96 & 0.32 & 1.12 & 0.96 & 7.60 \\
\hline 0.64 & 0.48 & 0.48 & 0.64 & 0.48 & 0.48 & 0.40 & 0.96 & 0.48 & 0.64 & 1.61 & 7.29 \\
\hline 0.80 & 0.72 & 0.32 & 0.72 & 0.56 & 0.48 & 0.96 & 1.69 & 0.16 & 0.48 & 1.12 & 8.01 \\
\hline 0.72 & 0.32 & 0.40 & 1.04 & 0.80 & 0.96 & 0.56 & 0.96 & 1.28 & 1.20 & 0.96 & 9.20 \\
\hline 0.24 & 0.24 & 0.24 & 0.56 & 0.72 & 0.32 & 0.64 & 1.77 & 0.16 & 1.20 & 1.93 & 8.02 \\
\hline 0.56 & 0.24 & 2.89 & 0.72 & 2.09 & 0.08 & 0.80 & 0.00 & 0.00 & 0.32 & 1.77 & 9.47 \\
\hline 0.72 & 0.48 & 0.96 & 0.88 & 0.64 & 0.64 & 0.40 & 0.80 & 0.24 & 0.32 & 1.20 & 7.28 \\
\hline 0.88 & 0.56 & 1.12 & 0.64 & 0.80 & 0.56 & 0.32 & 1.44 & 0.40 & 0.64 & 1.69 & 9.05 \\
\hline 0.96 & 0.64 & 1.28 & 0.96 & 0.96 & 0.72 & 0.24 & 1.28 & 0.48 & 0.48 & 1.93 & 9.93 \\
\hline 0.64 & 0.48 & 0.48 & 0.64 & 1.12 & 1.04 & 0.08 & 0.48 & 0.32 & 0.96 & 1.52 & 7.76 \\
\hline 1.04 & 0.16 & 1.04 & 0.88 & 1.20 & 1.28 & 0.32 & 0.24 & 1.52 & 0.00 & 1.28 & 8.96 \\
\hline 9.12 & 6.41 & 10.33 & 9.2 & 10.49 & 7.68 & 5.2 & 11.38 & 5.52 & 7.52 & 16.93 & 100 \\
\hline
\end{tabular}

Choice assay: Data from Figure 2 presented as percentage of adult greenbugs that had settled on each sorghum genotype in each pot after $24 \mathrm{~h}$. 


\section{Supplementary Table 3}

\section{Sorghum NAM parental lines}

Greenbug feeding activity

\begin{tabular}{lll}
\hline RTx430 SC265 & Segaolane
\end{tabular}

Total duration of pathway phase

$2.66 \pm 0.33$

$3.39 \pm 0.32$

$2.57 \pm 0.36$

Time to first probe

$0.09 \pm 0.05 \quad 0.09 \pm 0.06 \quad 0.21 \pm 0.10$

Total duration of non-probing phase

$0.32 \pm 0.11$

$0.51 \pm 0.32$

$0.44 \pm 0.17$

Time to first Sieve Element Phase

$2.25 \pm 0.35$

$3.04 \pm 0.45$

$1.92 \pm 0.38$

Total duration of sieve element

$4.35 \pm 0.31 \mathrm{a}$

$3.21 \pm 0.30 b$

$4.56 \pm 0.35 a$

phase

Total duration of xylem phase

$0.77 \pm 0.12 \mathrm{a}$

$0.35 \pm 0.07 b$

$0.86 \pm 0.11 \mathrm{a}$

Values represent mean time $(\mathrm{h}) \pm \mathrm{SE}$ spent by greenbugs on various activities in each $8 \mathrm{~h}$ of recording $(n=15)$. Different letters across each row represents significant difference $(P<0.05)$ in the time spent by greenbugs for the indicated activity on different sorghum NAM parental lines. 
Supplementary Table 4

\section{Statistics}

No-choice Assay

\begin{tabular}{|l|r|r|r|r|}
\hline \multicolumn{5}{|c|}{ Type III Tests of Fixed Effects } \\
\hline Effect & Num DF & Den DF & F Value & Pr > F \\
\hline treatments & 10 & 121 & 10.01 & $<.0001$ \\
\hline
\end{tabular}

\begin{tabular}{|c|c|c|c|c|c|c|c|}
\hline \multicolumn{7}{|c|}{$\begin{array}{c}\text { Differences of treatments Least Squares Means } \\
\text { Adjustment for Multiple Comparisons: Dunnett }\end{array}$} \\
\hline treatments & treatments & Estimate & Standard Error & DF & t Value & Pr $>|\mathbf{t}|$ & Adj P \\
\hline Ajabsido & RTx430 & 0.1680 & 0.07269 & 121 & 2.31 & 0.0225 & 0.1721 \\
\hline Macia & RTx430 & -0.04862 & 0.08581 & 121 & -0.57 & 0.5721 & 0.9994 \\
\hline P898012 & RTx430 & -0.01565 & 0.07088 & 121 & -0.22 & 0.8256 & 1.0000 \\
\hline SC1103 & RTx430 & -0.1366 & 0.06993 & 121 & -1.95 & 0.0531 & 0.3523 \\
\hline SC1345 & RTx430 & 0.1316 & 0.05877 & 121 & 2.24 & 0.0270 & 0.2012 \\
\hline SC265 & RTx430 & -0.2949 & 0.06745 & 121 & -4.37 & $<.0001$ & 0.0003 \\
\hline SC283 & RTx430 & 0.07077 & 0.08333 & 121 & 0.85 & 0.3973 & 0.9848 \\
\hline SC35 & RTx430 & -0.03244 & 0.08671 & 121 & -0.37 & 0.7089 & 1.0000 \\
\hline SC971 & RTx430 & 0.02387 & 0.05257 & 121 & 0.45 & 0.6506 & 0.9999 \\
\hline Segaolan & RTx430 & 0.3256 & 0.06030 & 121 & 5.40 & $<.0001$ & $<.0001$ \\
\hline
\end{tabular}

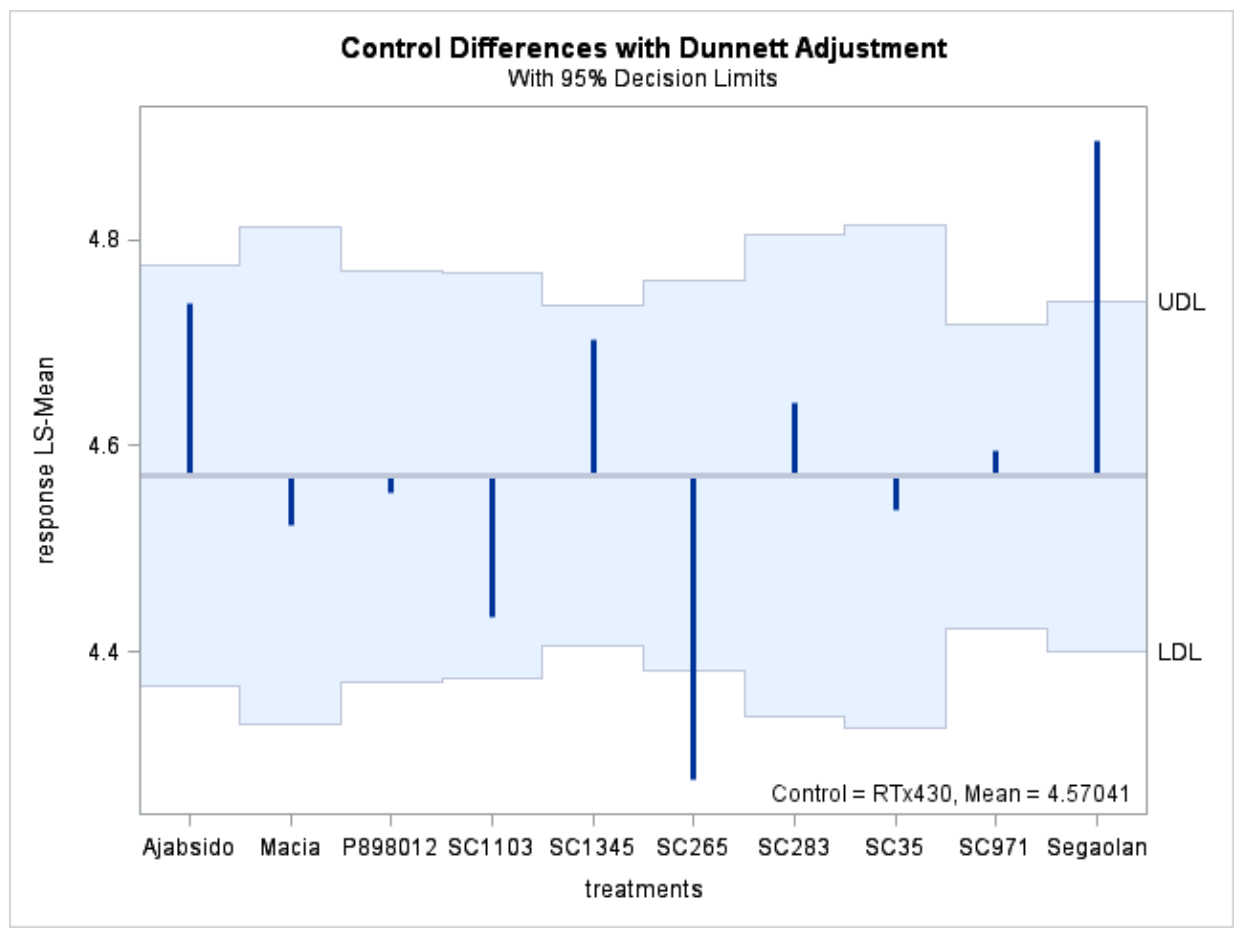


Choice Assay

\begin{tabular}{|l|r|r|r|r|}
\hline \multicolumn{5}{|c|}{ Type III Tests of Fixed Effects } \\
\hline Effect & Num DF & Den DF & F Value & Pr > F \\
\hline treatments & 10 & 121 & 10.35 & $<.0001$ \\
\hline
\end{tabular}

\begin{tabular}{|c|c|c|c|c|c|c|c|}
\hline \multicolumn{7}{|c|}{$\begin{array}{c}\text { Differences of treatments Least Squares Means } \\
\text { Adjustment for Multiple Comparisons: Dunnett }\end{array}$} \\
\hline treatments & treatments & Estimate & Standard Error & DF & t Value & Pr $>\mid \mathbf{t}$ & Adj P \\
\hline Ajabsido & RTx430 & -0.00873 & 0.1165 & 121 & -0.07 & 0.9403 & 1.0000 \\
\hline Macia & RTx430 & -0.3629 & 0.1520 & 121 & -2.39 & 0.0185 & 0.1626 \\
\hline P898012 & RTx430 & 0.1149 & 0.1616 & 121 & 0.71 & 0.4785 & 0.9978 \\
\hline SC1103 & RTx430 & 0.1303 & 0.1273 & 121 & 1.02 & 0.3081 & 0.9675 \\
\hline SC1345 & RTx430 & -0.1806 & 0.1615 & 121 & -1.12 & 0.2656 & 0.9428 \\
\hline SC265 & RTx430 & -0.5705 & 0.1575 & 121 & -3.62 & 0.0004 & 0.0042 \\
\hline SC283 & RTx430 & 0.2109 & 0.1747 & 121 & 1.21 & 0.2297 & 0.9105 \\
\hline SC35 & RTx430 & -0.5108 & 0.1846 & 121 & -2.77 & 0.0065 & 0.0615 \\
\hline SC971 & RTx430 & -0.2016 & 0.1758 & 121 & -1.15 & 0.2537 & 0.9335 \\
\hline Segaolan & RTx430 & 0.6069 & 0.09066 & 121 & 6.69 & $<.0001$ & $<.0001$ \\
\hline
\end{tabular}

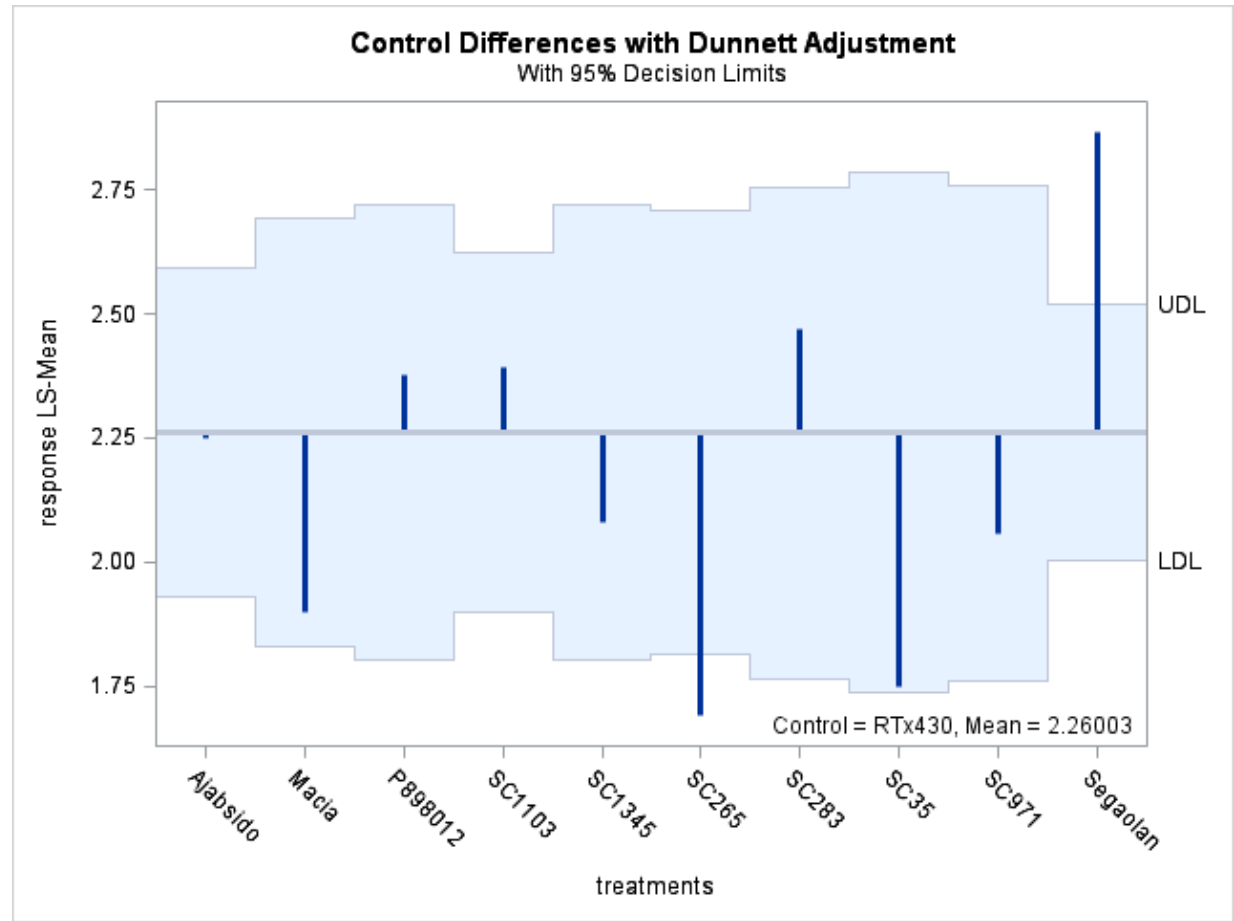

